\title{
La biografía como ancla: prensa y folletín chilenos del siglo XIX (1842-1881) ${ }^{1}$ \\ Biography Anchor: Chilean Press and Nineteenth Century Folletín
}

\author{
Marina Alvarado Cornejo \\ Universidad Católica Silva Henríquez \\ malvarado@ucsh.cl
}

El propósito de este artículo es estudiar las biografías difundidas en la sección folletín de la segunda parte del siglo XIX (1842-1881), distinguiendo los personajes de los que se cuenta su vida, los aspectos que se destacan de ellos y las funciones que este tipo de relato cumplió tanto para la sección folletín como para el medio escrito que lo difundió. El supuesto que organiza este trabajo plantea que la función del discurso autobiográfico fue conformar un repertorio de personajes vernáculos y reconocibles por los ciudadanos de esta joven nación que, si bien había alcanzado la independencia política de España, no lo había hecho desde las perspectivas cultural e intelectual, por esta razón este tipo de relato cumplió la función de ancla social, moral, nacional y cultural. Por tanto, los sujetos biografiados respondieron a necesidades organizacionales del país y sus distintas esferas de desarrollo. Este trabajo contempla tres partes: la primera trata acerca de la sección folletín, su inclusión en la prensa local y sus proyecciones. La segunda analiza la producción biográfica-folletinesca. Se cierra el trabajo con las conclusiones.

Palabras clave: Biografías folletinescas, prensa chilena, siglo XIX.

The purpose of this article is to study the spread biographies in folletín of the second part of the nineteenth century (1842-1881) section, distinguishing characters whom his life, aspects that stand out from them and the functions that this kind of story fulfilled for both serial section as written for the average spread it. The course organized by this paper proposes that the function of auto-biographical speech was forming a repertoire of vernacular and recognizable characters by citizens of this young nation, although it had achieved political independence from Spain, it had not done since the prospects cultural and intellectual, therefore this kind of story fulfilled the role of social anchor, moral, national and cultural. Therefore, the biographees subjects responded to organizational needs of the country and its various fields of development. This work includes three parts: the first is about the serial section, its inclusion in the local press and projections. The second analyzes the bio-feuilleton production. working with the conclusions closes.

Keywords: Folletinescas biographies, Chilean press, XIX Century.

Recibido: 24/04/2016

Aceptado: 23/10/2016

\footnotetext{
1 Este trabajo forma parte del proyecto FONDECYT Regular No 1140222, titulado "La sección folletín de la prensa en Chile (1842-1900): inclusión, difusión y transformación de una sección que fue mucho más que novelas por entrega", patrocinado por la Universidad Católica Silva Henríquez, y del que soy la investigadora responsable.
} 


\section{Introducción}

Aunque el folletín alcanzó reconocimiento y fama en la época de su surgimiento, y hasta hoy, por el material narrativo que allí se difundió, al punto de entenderse la palabra "folletín" como novela facsimilar o por entregas, lo cierto es que este no fue el único producto que bajo ese nombre apareció en la prensa chilena a partir de 1842, fecha en la que se incorporó la sección denominada folletín y cuya principal cualidad fue la difusión de textos de diversa índole temática y estilística como comentarios sociales, literarios, culturales, políticos, poemas largos y biografías. Dentro de las investigaciones que destacan esta especificidad de la sección folletín, destacan el trabajo de Álvaro Barros Lémez (1992) y Hernán Pas (2015); el primero profundiza en la ruta histórica de la sección. En tanto que Pas trabaja con la relevancia que tuvieron los discursos difundidos por la sección para el desarrollo de la opinión pública, la modernización de la prensa, la educación y la civilización de la Nación tanto en Chile como Argentina.

La sección folletín fue introducida a Chile por Juan Domingo Faustino Sarmiento y el diario El Progreso, que en ese entonces él dirigía. La propuesta sarmientina planteaba que el folletín se constituiría en una sección permanente en la que se tratarían distintos asuntos, a la usanza de los periódicos de Francia, pero lo más importante es que cada uno de ellos serían desarrollados por entendidos en dichos aspectos de la vida cotidiana como moda, literatura, cultura, arquitectura, comercio, historia, etc., por tanto no solo se informaría al público, sino que además se le aconsejaría. El Progreso fue el precursor del folletín pero no el único periódico que lo incorporó, debido a que un número considerable de diarios y revistas culturales chilenos de la época se apropiaron también de dicha sección siguiendo el criterio de Sarmiento.

Para efectos de este trabajo, el propósito es estudiar las biografías difundidas en la sección folletín de la segunda parte del siglo XIX (1842-1881), distinguiendo los personajes de los que se cuenta su vida, los aspectos que se destacan de ellos y las funciones que este tipo de relato cumplió tanto para la sección como para el medio escrito que lo publicó. El supuesto que organiza este texto plantea que la función del discurso biográfico fue conformar un repertorio de personajes vernáculos y reconocibles por los ciudadanos de esta reciente nación que, si bien había alcanzado la independencia política de España, no lo había hecho desde las perspectivas cultural e intelectual, en consecuencia, este tipo de relato cumpliría la función de ancla social, moral, nacional y cultural. Por tanto, los sujetos biografiados respondieron a necesidades organizacionales del país y sus distintas esferas de desarrollo.

Este trabajo contempla tres partes: la primera trata acerca de la sección folletín, su inclusión en la prensa local, sus proyecciones y el conflicto de la modernidad. La segunda analiza la producción biográfica-folletinesca, a partir de la "situación biográfica", es decir, de la consideración del lugar desde donde se cuentan esas vidas, en palabras de Carlos Piña (1988), "desde qué ubicación temporal, social, espacial, etc., la relatan. En definitiva, la situación biográfica está constituida por la suma y combinación de todo aquello que en un instante en el tiempo posee solo ese individuo" (24); en tanto que el 
espacio biográfico lo entenderemos en el mismo sentido de Leonor Arfuch (2002), es decir, "como horizonte de inteligibilidad" (18). Se cierra el trabajo con las conclusiones.

\section{Marcas de modernidad y prensa chilena del siglo XIX}

El período dentro del que se enmarca este trabajo es caracterizado tanto por los historiadores de las ideas y la cultura como para los historiadores latos como de comienzo de la "Modernidad" en Chile (y Latinoamérica). Todos ellos, indistintamente de sus especialidades e intereses, coinciden en que es altamente problemático caracterizar y entender la "modernidad" en el contexto latinoamericano y, por tanto, en el chileno.

Bernardo Subercaseaux señala que se hace uso del concepto modernidad, en términos generales, "para referirse a una gran época histórica o a la experiencia vital contradictoria de quienes experimentan esas transformaciones" (1997 90). Jorge Larraín (1997), por su parte, acota la "situación de la modernidad" para el caso latinoamericano, indicando que "desde principios del siglo XIX la modernidad se ha presentado en América Latina como una opción alternativa a la identidad tanto por aquellos que sospechan de la modernidad ilustrada como por aquellos que la quieren a toda costa" (314). Más adelante, Larraín observa que "la modernidad latinoamericana comienza [...] más tarde, a principios del siglo XIX, con la independencia, porque España y Portugal lograron impedir su expansión durante tres siglos" (319). En esta preocupación por ordenar y entender mejor el proceso, el historiador determina la existencia de fases, en donde la primera, ubicada en el diecinueve, carga con una cierta contradicción y la denomina como oligarca por su "carácter restringido" (Larraín 319). Este período tiene la cualidad de que, además, se adoptan ideas laicas, liberales, se instalan las bases para la construcción de un Estado republicano, se incorporan prácticas democráticas en el gobierno, lo que no es garantía ni sinónimo de que se otorga participación amplia al pueblo. Es por ello que la modernidad de este siglo fue más bien política, cultural y prospectiva, pero no económica, ya que no hubo desarrollo de una industria que permitiera abandonar el sistema exportador de materias prima.

La existencia de una "experiencia de la modernidad" en América Latina es lo que propone Julio Pinto (2000), la que se habría iniciado a mediados del siglo XIX. Esta experiencia, señala, "cobró la forma de un proyecto, mientras que para otros [actores sociales] -los más- se trató más bien de una ruptura impuesta en contra de su voluntad" (2). Pinto indica que aquellos grupos sociales que en un inicio del proceso de modernidad estaban más escépticos, finalmente fueron quienes, hacia fines del 1800, adhirieron con mayor compromiso. Dentro de este grupo habrían estado los intelectuales, especialmente aquellos interesados en el desarrollo de las letras; ciertamente, Ángel Rama (20014) explica que

lo realmente cierto fue la idealizada visión de las funciones intelectuales que vivió la ciudad modernizada, fijando mitos sociales derivados del uso de la letra que servían para alcanzar posiciones [...] la letra apareció como la 
palanca del ascenso social, de la respetabilidad pública y de la incorporación a los centros de poder (103).

Esto se materializó en que los escritores podrían ahora ser reporters o bien vender sus artículos a los periódicos, o piezas teatrales a compañías o bien dedicarse a la enseñanza. Las nuevas posibilidades derivaron en que nuevos actores dificultaran el entramado social, ampliaran el circuito letrado y que nuevas instituciones los promovieran. Como indica Julio Ramos (2003):

más que una cuestión de empleos o de profesionalización y mercantilización de la escritura, la emergencia de la literatura 'pura' [...] en contraste con la función estatal de las letras, es resultado de la reestructuración del tejido de la comunicación social, que sacudió los sistemas de autorización presupuestos por la producción literaria anterior a fin de siglo (93).

El marco de las publicaciones periódicas chilenas desde 1842 forma parte de lo que en trabajos anteriores hemos determinado como "segundo momento: la revista como trinchera de resistencia" (Alvarado Revistas culturales), caracterizado porque

forjaron una lucha en pro de la prensa periódica específica. Esto es, las revistas abogaron por la incorporación de una cultura letrada nacional y, además, se preocuparon por la nacionalización y profesionalización de la literatura. El criterio estético permitió brindarles mayor libertad a sus autores, por lo que se reconocieron como publicaciones ubicadas a medio camino entre libro y el diario; entre la lectura extensiva y la intensiva (Alvarado 59).

Juan Domingo Faustino Sarmiento fue proyectista y protagonista para alcanzar los propósitos antes indicados, y esto lo hizo con las innovaciones editoriales que levantó en Chile. El trasandino inspirado en lo que vio de la prensa parisina, señaló que "un buen folletín puede decidir de los destinos del mundo dando una nueva dirección a los espíritus" (Ct. en Laera 2003, 417), razón por la que en el primer número de ese diario instaló las bases respecto del material escritural que allí se debía publicar, señalando que,

Nuestro folletín será para el solaz del espíritu [lo] que los postres son para el regalo del paladar [...] Las modistas parisienses Mlle. O. y Mlle. V. nos instruirán de vez en cuando del jénero (sic) del vestido [...] Las tertulias, los conciertos y reuniones [...] formarán algunas veces el fondo de un folletín [...] Tendrán en este lugar privilegiado, grata y cordial acojida ( $\mathrm{sic}$ ) los ensayos literarios de nuestros jóvenes, [...] nos acercaremos el lunes a la Sociedad de Agricultura [...] Otro tanto haremos con la Sociedad Literaria que promete frutos [...]

(El Progreso, No 1, 1842, s/d). 
El proyecto del autor del Facundo en Chile, por medio del folletín, tuvo logros y alcances novedosos, incluso si se le compara con la prensa de su país de origen, cuestión que corroboramos con lo que señala Alejandra Laera (2003), quien explica que en la prensa chilena [la sección alcanzó un] "aggiornamento [...] [que] no había alcanzado en la prensa rioplatense" (418), porque en la prensa argentina del siglo XIX la principal función del apartado fue difundir novelas y no la gran cantidad de material escritural, híbrido, temática y estilísticamente, que en la prensa chilena sí logró. Sarmiento, consciente de esto, en el número previo a dejar la redacción de El Progreso en 1845 expuso que en el folletín

se deslizaba cual oculto veneno, encapotado bajo el título indiferente de variedades, como los jesuitas se introducen en todos los países de donde han sido expulsados, bajo el nombre de padres del Sagrado Corazón [...] iAlmas inocentes! [los lectores] que no veían el veneno con que se iba a corromper la moral pública!

(El Progreso, 30 de agosto de 1845, s/d)

Esta sección se reprodujo en la demás prensa de la época (tanto en su opción de sección de "variedades" como de novelas por entrega), pese a que, como indica Hernán Pas (2015), los textos que allí se reproducían no eran considerados morales ni promotores de buenas costumbres, cuestión que estaba en línea con aquella postura de

índole republicana e ilustrada que al calor del proceso revolucionario abogaba por la formación ciudadana y procuraba, por ende, el diseño de una biblioteca conveniente, esto es, un tipo de lectura acorde con lo que se esperaba de esa nueva subjetividad republicana.

Pese a esto, la prensa chilena vio en el folletín una posibilidad cierta de crecimiento y expansión, pues encontraron en sus juegos de suspenso, pausa e intervención, una posibilidad de venta y suscripción fiel (que efectivamente les funcionó).

En otro aspecto, los periódicos se estaban jugando la construcción y delimitación de la nación desde una perspectiva intelectual e ideológica con el propósito de afianzar la independización efectiva y cultural para, de ese modo, derrocar, finalmente, el espíritu colonial2. Respecto del lector, como indica Pas (2012), este también cambió, pues desde ese momento tenía interés en

\footnotetext{
2 Acerca de esto, es importante señalar que a fines del siglo XIX la Colonia es metaforizada en distintos textos (novelas, comentarios, ensayos, etc.), como un período oscuro, lleno de ignorancia. Muestra de esto es la novela Casa Grande, de Orrego Luco, la que por medio de su trama demuestra la crisis que el choque entre la Colonia y la Independencia dejó entre los personajes allí involucrados.
} 
la escena pública, por ello los periódicos se constituyeron en mediadores y agentes privilegiados para la conformación de la opinión pública ${ }^{3}$.

Beatriz Sarlo en Una modernidad periférica... (1988), señala que "cuando en la sociedad hay cambios acelerados, se suscitan sentimientos de incertidumbre, los que llevan a evocar restos que la memoria conserva" (31). Bajo este contexto, de una modernidad trasplantada y, en gran medida impropia, las biografías publicadas en el folletín van a funcionar como parte del despliegue de estrategias programáticas que caracterizó a la época, y además, van a intentar subsanar la orfandad, de la que habla Sylvia Molloy (1996) y Lorena Amaro (2002) en donde quedaron sumidas las nuevas repúblicas americanas.

\section{Leonor Arfuch explica que}

La sola mención de lo "biográfico" remite, en primera instancia, a un universo de géneros discursivos consagrados que tratan de aprehender la cualidad evanescente de la vida, oponiendo, a la repetición abrumadora de los días, a los desfallecimientos de la memoria, el registro minucioso del acontecer, el relato de las vicisitudes o la nota fulgurante de la vivencia [...] [las] biografías [...] dan cuenta de [...] esa obsesión de dejar huellas [...] de ese énfasis en la singularidad que es a un tiempo búsqueda de trascendencia (17).

La escritura biográfica, entonces, da cuenta de este vuelco hacia el individuo, es decir, de la concentración de información y atención respecto de la historia de una vida que, pese a ser muy distante de la religiosidad, fue alzada hacia un cierto nivel de santificación antropocéntrica. Esta cuestión está en línea con la progresiva laicización del Estado chileno, la que en el siglo XIX en Chile fue impulsada por el creciente ascenso del partido Liberal, teniendo como capítulo fundamental el impulso de las leyes laicas por parte del presidente Domingo Santa María y la posterior elección del presidente de dicha bancada Manuel Balmaceda. En definitiva, el relato de una vida secular va de la mano del alejamiento de la religiosidad, lo que deviene en la búsqueda de explicaciones, justificaciones y fundamentaciones históricas, sociales, políticas, culturales, etc., en personas/personajes con fecha de nacimiento y muerte civilmente reconocidas.

La preocupación por una vida particular que subraya la especificidad del individuo radica, para el contexto en el que nos enmarcamos, en la búsqueda y asentamiento de sujetos colectivos que dieran sentido a la incipiente

3 La opinión pública la entendemos desde Hannah Arendt, quien señala que lo que verdaderamente existe es una esfera pública, la que, "al igual que el mundo en común, nos junta y no obstante impide que caigamos uno sobre otro, por decirlo así. Lo que hace tan difícil de soportar a la sociedad de masas no es el número de personas, o al menos no de manera fundamental, sino el hecho de que entre ellas el mundo ha perdido su poder para agruparlas, relacionarlas y separarlas" (2009: 62). 
Nación ${ }^{4}$ y, a su vez, ya más hacia 1870 , el desarrollo de la opinión pública (Habermas 1994), aunque entendiendo las limitaciones y desigualdad de la misma. Contar una vida, por consiguiente, pone en tensión la dicotomía de lo público y lo privado, cuestión que para el siglo XIX responde a la visión dualista propia del mundo burgués y a "la vivencia de un 'yo' sometido a la escisión [...] sentimiento/razón; cuerpo/espíritu; hombre/mujer" (Arfuch 34). A las categorías inscritas por Arfuch, agregamos las de civilización/ barbarie; Independencia política/Independencia intelectual; y colonialidad/ proyecto emancipatorio. La pregunta que es posible hacer ahora es ¿por qué las biografías de la sección folletín se constituyeron en lectura apetecible para el limitado grupo de alfabetos que frecuentaba estos periódicos decimonónicos? Responder esta cuestión no es simple, ya que las noticias que tenemos acerca de las predilecciones de los letrados en dicha centuria las conocemos si llevamos a la práctica lo que Roger Chartier (2005) nos señala acerca de las prácticas lectoras, indicando que:

Contra una definición puramente semántica del texto, hay que señalar que las formas producen sentido y que un texto estable en su escritura está investido de una significación y de un estatuto inéditos cuando cambian los dispositivos del objeto tipográfico que propone su lectura.

Se debe señalar también que la lectura es siempre una práctica encarnada en gestos, espacios, costumbres.

La sección folletín tenía como propósito captar la mayor cantidad de lectores posibles, razón por la que los temas abordados, el lenguaje utilizado, el tono y los tipos discursivos allí difundidos (lo que hoy entenderíamos como comentario social, o de algún hecho cultural o literario, poemas largos) eran cada vez distintos; tanto así que esta sección, ya casi cerrando el siglo XIX, pasó a llamarse "Variedades". Esta situación está en línea con lo que indica Julio Ramos, pues "el periódico [y todos sus componentes] no solo cristalizaba la 'racionalidad', el orden que se identificaba con la estabilidad y delimitación nacional, sino que permitía extender ese orden a las zonas insubordinadas de la 'barbarie'. Convertir el 'bárbaro' en lector [...]" (126). Otro antecedente que aporta a este tema lo entrega Álvaro Fernández Bravo (1997),

[...] al abogar a favor de una lengua escrita que reflejara con mayor fidelidad el habla popular de los chilenos, Sarmiento no solo desafiaba el apego a la norma peninsular recomendada por el intelectual caraqueño [Andrés Bello], sino que consideraba este un gesto necesario para la independencia cultural (143).

\footnotetext{
4 El concepto de Nación lo entendemos conforme lo desarrolla y problematiza Álvaro Fernández Bravo (1997), quien desarrolla la idea de un nacionalismo cultural por sobre un nacionalismo geográfico.
} 
Los autores de folletín se daban ciertas licencias temáticas que en otras no se permitían; ejemplo de esto es que aquí fueron comunes los juegos autoriales como la pseudonimia, como es el caso de Diego Barros Arana, quien tras el seudónimo de "Bálsamo" comentaba acerca de las Bellas Artes en el periódico El Museo de 1854, tema inusual leer Barros Arana en otros medios escritos y explayarse del mismo modo. Otra cualidad relevante y que hizo de esta sección un espacio habitual, es que se comentaran asuntos noticiosos que habían captado recientemente la atención del mismo y de otros periódicos, y en los que se realizaba un comentario que profundizaba y polemizaba el hecho.

Las biografías de la sección folletín pudiesen parecer entonces "desubicadas" debido a la extemporaneidad de las mismas; no obstante ello, esta "divergencia temporal", como la denomina Arfuch, es salvada en estos escritos ya que una de las cualidades principales de ellas es que además de figurar el respectivo rótulo "Folletín" y luego "Biografía de...", le sigue "...y noticias acerca de él". Por tanto, el efecto de actualidad se supera, lo mismo que la referencialidad (se ancla en un nombre), más la objetividad y novedad que asegura el hecho noticioso, se logra entonces captar el interés y atención del lector en esta más compleja "red de veridicción" (Arfuch 47).

\section{Trayectorias biográficas}

La dificultad de revisar la situación biográfica de textos difundidos en la prensa, desde la perspectiva metodológica, nos lleva a que nuestra mirada deba ser doble, ya que no solo importa quién la escribió y sobre quién, sino además por qué ese medio decidió publicarlos. Esta constatación nos obliga a seguirle el hilo al medio escrito, sumado a los elementos paratextuales, puntualmente peritextuales, que otorgarán significado al texto (título, explicación, notas que lo acompañan, etc.).

Consideramos que existieron ciertos modelos o pautas biográficas muy recurrentes, y de las que expondremos algunos tipos más representativos. El primer tipo corresponde al "héroe europeo". El segundo, "héroe americano europeizado". El tercero, "biografía pública con elementos privados válidos para la vida pública". El cuarto, la "biografía retórica". El quinto, "el héroe ilustrado local".

Tras la constatación de las principales peculiaridades de los folletinesbiográficos, es clarísimo que uno de los conceptos clave que se reitera es la del héroe, el que, en palabras de Manuel Alvarado (2016), es una

noción que se vuelve fundamental y problemática durante el siglo XIX latinoamericano, ya que tras las luchas de la Independencia, en todas las nuevas repúblicas los políticos e intelectuales se vieron enfrentados a la necesidad de crear un imaginario capaz de cohesionar y unificar simbólicamente a los nuevos ciudadanos [...] la figura heroica decimonónica tiene una inspiración en la realidad histórica en la medida en que los personajes ensalzados efectivamente existieron [...] 
Julio Pinto (2000), por su parte, indica que el intento por levantar el proyecto de modernización

corrió por cuenta de la Independencia, una de cuyas principales tareas fue precisamente reemplazar el Estado monárquico y corporativo colonial por un Estado republicano y nacional [...] ese objetivo se consiguió bien avanzado el siglo XIX [...] en los diseños utópicos elaborados por ideólogos y 'próceres' que intentaron dar alguna dirección al proceso de construcción nacional".

Esto último es coherente con lo que explica Pierre Bourdieu (2011) en la "ilusión biográfica", ya que el sociólogo indica que el biógrafo es, ante todo, un ideólogo que inspira su relato "en el deseo de dar sentido, dar razón, extraer una lógica a la vez retrospectiva y prospectiva, una consistencia y una constancia, estableciendo relaciones [...] en función de una intención global" (122).

Respecto de la construcción discursiva de las biografías, los autores de estos textos utilizaron las formas de escritura que estaban disponibles para ellos en la época, es decir, no innovaron en los estilos escriturales, pese a que el tema y las intenciones fuesen novedosas tanto para los escritores como para los lectores. Acerca de esto, Elvira Narvaja de Arnoux (2008) explica que lo que los intelectuales del siglo XIX hicieron fue reproducir la tradición retórica que se asentó a fines del siglo XVIII a partir de los requerimientos surgidos de la difusión de la cultura escrita, dentro de ellas se ubicó con privilegios la prosa informativa, teniendo en cuenta que los años 1800 fueron reconocidos como los años donde dominó el periódico, en tanto que en los 1700 lo hizo el libro. De hecho, las formas de escribir responden a la necesidad por consolidar el espacio "de la lengua y del Estado. Este necesita para consolidarse la construcción de un imaginario colectivo, para ello la representación de la lengua que suministra la escritura es un soporte importante" (2006 53).

Para el primer caso, "el héroe europeo", el periódico El Progreso es una muestra irrefutable, ya que dentro de los personajes que biografiaron se encuentran solo personajes del "Viejo Mundo", teniendo especial afición por miembros de la realeza española previos a la era Borbón (Carlos V) y, como el caso que ejemplificaremos, ingleses.

Biografía de Lord Wellington

En los anales de Inglaterra fue un día memorable aquel en que llegó a su término la inmensa cuestión de la emancipación católica de Irlanda. Esta medida, que de golpe llamó a la vida civil y política, de dos a tres millones de hombres, ajitó (sic) violentamente los espíritus; el anglicanismo prorrumpió en fuerte vocería; los diarios ultra-toris cada mañana tenían un acceso de epilepsia [...] Durante veinte años de guerra, solo él puede decir que 
jamás la derrota deshonró su nombre; sin haber recibido de la naturaleza esa audacia de la inspiración, ese fuego sagrado que constituye el jenio (sic), triunfo del mayor jenio (sic) moderno [...]

(El Progreso, No 83, 18 de febrero 1843, s/d)

El periódico sarmientino dio muestras evidentes del vuelco de mirada hacia Inglaterra y Estados Unidos, ambos sitios vistos como cuna de la modernidad, pensamiento liberal y todo lo que ello implicaba, entre eso, la laicización del país.

El segundo tipo biográfico, "el héroe americano europeizado", es sin lugar a dudas el más reiterado y común dentro de la gama de biografías de la prensa de la época. Muestra de este caso son los textos difundidos por el periódico La Patria de 1845, editado en Concepción. Una de las biografías allí difundidas fue la del "Jeneral (sic) San Martín", a lo largo de siete números. Esta apareció firmada por Ricardo Gual y Jaen, el que corresponde al seudónimo de Juan García del Río5, quien originalmente publicó este texto primero en Londres y luego fue reimpreso por Río en Lima en 1823.

En este texto, San Martín es comparado con Aníbal y Napoleón, mientras que la cordillera de los Andes es comparada con los Alpes:

\section{Biografía de El Jeneral San Martín}

Acompañada de una noticia de su estado presente y otros documentos importantes

No puede apreciarse jamás debidamente en Europa el mérito verdadero de los campeones de la independencia americana; porque no se tiene idea de las dificultades de todo jénero con que han tenido que luchar. Apenas se concibe, en efecto, ni aun por los mismos que han sido testigos oculares, como ha creado San Martín, de la nada por decirlo así, en una provincia pobre, y en el estado en que acabamos de describir a las del Río de la Plata, el ejército que dio libertad a Chile: solo su jenio (sic), su infatigable empeño, su fecunda imajinación (sic), podían haber levantado y sostenido allí una fuerza, engañado al enemigo $[\ldots]$

\footnotetext{
5 Juan García del Río fue un literato y político oriundo de Nueva Granada (Bogotá). Antes de dar curso a la publicación y dirección de El Museo de Ambas Américas (1842), durante 1826 y 1827 publicó en Londres junto con Andrés Bello las revistas Biblioteca Americana y Repertorio Americano, "destinada[s] a difundir en los países de habla hispánica todos aquellos conocimientos de derecho público, científicos y literarios que pudieran ser de alguna utilidad en otras naciones" (Vilches, Roberto. Las revistas literarias chilenas del siglo XIX, p. 10). La publicación fue dirigida y redactada por Manuel Rivadeneira, en esos años, editor de El Mercurio.
} 
Esta biografía es ejemplo, además, del tercer tipo reiterado que constatamos, "biografía pública con elementos privados válidos para la vida pública". A nivel formal, este tipo de escrito se compone de una primera parte que funciona como exordio y luego la narración de ciertos acontecimientos en torno al personaje central del texto. El final de la biografía, en tanto, no concluye los argumentos entregados a lo largo de la narración, sino que inicia una historia nueva que perfectamente podría ser continuada o desarrollada con mayor profundidad, sin embargo, pareciera ser que el sujeto que enuncia la historia se "muerde los labios" y recordara el propósito central de su escrito:

A poco tiempo de su llegada a Buenos-Aires, casó San Martín con doña Remedios Escalante de la Quintana, hija de una de las familias más distinguidas del país, joven, hermosa, de excelente educación, de modales mui finos y dotados de las mas bellas cualidades. Una hija tan solo han tenido por fruto de su unión; y a esta va a dedicar San Martín el resto de su vida, después de haber consagrado la mas preciosa parte de ella a la libertad y la felicidad de América.

(La Patria, 22 de noviembre de 1845, s/d)

El cuarto caso es la "biografía retórica", la que constatamos en la "Biografía del Jeneral Don Manuel Bulnes Presidente de la República de Chile". El autor de este texto es Juan Bautista Alberdi quien, junto con publicar este trabajo en La Patria, también lo hizo en forma de libro, el mismo de su difusión en este periódico, lo que nos dificulta la tarea para determinar cuál fue primero. La propiedad de este tipo biográfico es su perfección respecto de la disposión discursiva que Aristóteles ${ }^{6}$ estimó. En primer lugar, se presenta el exordio:

Biografía del Jeneral (sic) Don Manuel Bulnes Presidente de la República de Chile

El menor de los obstáculos que ofrece la redacción de la biografía completa del Jeneral (sic) Bulnes, es el de que su vida se halla en la mitad de su carrera; pudiéndose añadir a este el de la falta de trabajos auxiliares, a los que es necesario suplir por el improbo estudio de documentos inéditos i ( $\mathrm{sic}$ ) dispersos, no siempre de fácil consulta. Conspira no menos a favor de estas dificultades una mal

\footnotetext{
6 De acuerdo con la Retórica de Aristóteles (1999), el orden del discurso considera que "Dos son las partes del discurso, ya que por fuerza se ha de exponer la materia de que se trata y, además, hay que hacer su demostración, demostrar sin hablar previamente; porque demostrar implica algo que demostrar y decir algo previamente tiene por causa demostrarlo. De estas dos partes, una es la exposición y otra la persuasión, del mismo modo que se distingue entre el problema y la demostración [...] Por lo tanto, en resumen, las partes necesarias son solo la exposición y la persuasión. Estas son, pues, las propias; y, a lo máximo, exordio, exposición, persuasión y epílogo" (555-556-557).
} 
entendida modestia, que mantiene sombríos muchos rasgos airosos de la historia chilena.

Cabe, en efecto, a los hombres eminentes de Chile la suerte que a su país mismo, en cuanto sus sobresalientes cualidades aparecen a la vista del mundo veladas de un manto de modestia, no sin inconvenientes capaces de balancear las ventajas.

(La Patria, 19 de agosto de 1845, s/d)

Le sigue la narratio o narración:

Solo desde 1839, con motivo de la guerra del Perú, se oye por primera vez repetir en las naciones estranjeras (sic) el nombre del Jeneral Bulnes como el de un guerrero distinguido. Los más de sus hechos anteriores no son bastante conocidos aun en su propio país.

(La Patria, 19 de agosto de 1845, s/d)

Continúa la proposición del discurso, en el que Alberdi instala dos temas clave; primero, la necesidad de construir y progresar tomando en consideración los aprendizajes que dejaron las guerras de la independencia:

I (sic) no solamente han cambiado de dimensiones los acontecimientos i (sic) cosas pertenecientes a la América política en los últimos tiempos; sino que también han adquirido un carácter diferente. Las necesidades de ahora veinte años no son las de hoi (sic). En aquel tiempo se trataba de disolver i (sic) destruir; hoi (sic) se trata de conservar i (sic) organizar.

(La Patria, 2 de septiembre de 1845, s/d)

La segunda idea, en tanto, plantea la relevancia por dar mayor importancia a los personajes públicos americanos:

Sea cual fuere el valor i (sic) carácter de los hechos i (sic) personajes que ofrezca la América política de estos momentos, es indudable que la vida de sus hombres públicos es del más indispensable estudio [...] Para convencerse de que el Jeneral Bulnes se halla en el número de estos, no hai (sic) mas que ojear las pájinas (sic) históricas de los últimos catorce años en Chile.

(La Patria, 2 de septiembre de 1845, s/d)

Continúa Alberdi con la presentación de la división o partitio, la que transcribimos tal y como apareció en el periódico: 
Así, dividiendo el cuadro de su vida, en los periodos que componen la historia de los últimos 36 años, vamos a hablar sucesivamente:

1. ${ }^{0}$ - De su primera edad i (sic) servicios en la guerra de la Independencia.

2. ${ }^{\circ}$ - De sus servicios en la guerra contra los españoles unidos a los indios.

3. ${ }^{0}$ De sus campañas contra los indios unidos a salteadores i (sic) bandidos.

4. - De su campaña contra la confederación Perú-Boliviana.

5. - De sus trabajos en la Presidencia de la República.

(La Patria, 5 de septiembre de 1845, s/d)

Cierra el publicista argentino con la peroración o peroratio, en donde transparenta la argumentación que subyace a la biografía de Manuel Bulnes:

En América todo principia, todo está recientemente en aprendizaje, en la hora de los ensayos; la libertad lo mismo que la oposición, la oposición lo mismo que el gobierno. La inexperiencia, la impericia, son males que pesan sobre todos.

(La Patria, 24 de octubre de 1845, s/d)

El interés de Juan Bautista Alberdi en desplegar sus propuestas siguiendo el modelo retórico visto, se afirma en la necesidad del intelectual por interferir, como indica Carolina Barros (1997), "Alberdi solo buscaba reacción. Y para ello no cabía otro canal que el de la prensa, esa nueva plataforma para el cabildeo" (7).

El siguiente folletín biográfico fue difundido por el periódico La Linterna, de 1867 , medio que tenía como propósito continuar con el incentivo a la originalidad en la literatura chilena, tarea que asumen había sido iniciada por José Victorino Lastarria en El Semanario de Santiago en 1842 . El sujeto de esta biografía es el coronel Nicolás Maruri, sobre quien señalan que:

Después de las gloriosas guerras de la Independencia, donde se distinguió particularmente Maruri, fue en la contra-revolución que hizo al Coronel Campino; revolución que relataremos con alguna detención por la triple circunstancia de ser un hecho importante, glorioso para su memoria $[\ldots]$

(La Linterna, № 6, 29 de septiembre de 1867, s/d) 
El cambio de personajes de las biografías y de propósitos de las mismas lo observamos con mucha fuerza desde 1870, aproximadamente, periodo en el que, de acuerdo con Julio Pinto, "Ios herederos del utopismo independentista depositaron esa misma fe constructivista en el Estado liberal que emergió durante la segunda mitad del siglo XIX [...] La consigna de 'civilización o barbarie' enarbolada por Sarmiento y los modernizadores argentinos" (Pinto 10). La Revista Americana de 1869 es un caso valioso entre las publicaciones periódicas que revisamos, tanto por su proyecto periodístico como el tipo de folletín-biográfico que difundió. Para conocer y comprender la "situación biográfica" de los relatos de una vida aquí aparecidos, el prospecto de este periódico es clave:

Los pueblos americanos que, con los mismos deseos i (sic) por idénticos caminos, persiguen preciosos bienes de la vida republicana democrática, viven aun aislados sin que exista entre ellos aquellas relaciones íntimas, aquel cambio constante de ideas i conocimientos intelectuales $[\ldots]$.

El triunfo de la revolución americana no solo devolvió a los pueblos sus derechos políticos sino que libertó a las intelijencias (sic) del ominoso yugo de la ignorancia, en cuyas borrosas tinieblas jimieron envueltas durante los trescientos años del dominio estranjero (sic).

En América tan solo había esclavos i tiranos, las letras i las artes no podían levantar cabeza en donde la ambición i la crueldad se lo absorbían todo.

(La Revista Americana, 29 de agosto de 1869, s/d)

El prospecto orienta acerca de las biografías aquí publicadas, las del quinto tipo que llamamos "el héroe ilustrado local". La primera, escrita por Carlos Boizard Huidobro, abogado y militante del Partido Liberal, fue dedicada a Andrés Bello:

Entre los varones ilustres que ha producido la América desde su emancipación política hasta nuestros días, descuella en primera línea la prominente figura del sabio, erudito i (sic) venerable don Andrés Bello.

Hombre de ciencias i (sic) de letras, de consejo i doctrina, su nombre no fue pronunciado en las reñidas batallas de la Independencia $[\ldots]$

Sus títulos se hallan en los archivos de las oficinas diplomáticas i (sic) su hoja de servicio en las innumerables pájinas (sic) de las obras monumentales que escribió.

(La Revista Americana, 29 de agosto de 1869, s/d) 
Este tipo de biografías, reiteradas posteriormente en periódicos como La Linterna (1867), Las Bellas Artes (1873) y El Curioso Ilustrado (1881), ponen énfasis en aquello que anunciáramos anteriormente: el paso desde la independencia política hacia la independencia cultural e intelectual.

\section{Conclusiones}

El estudio de los folletines biográficos que llevamos a cabo en este artículo, nos permitió constatar que, las vidas respecto de las que se habla en el siglo XIX, más que dar tanto cuenta de las historias particulares de los biografiados, nos permitió observar el modo en que los autores y los periódicos que los publicaron estaban construyendo y proyectando en torno a la nación, la independencia cultural e intelectual, el universo simbólico local, los lineamientos políticos y los sociales. Por tanto, los personajes centrales de cada biografía son un nombre ancla que le otorga veracidad e historicidad a la serie de planteamientos organizados en cada escrito. En este sentido, la estrategia del folletín biográfico reafirma lo que durante este trabajo indicamos, esto es, que el siglo diecinueve fue más bien una centuria de proyectos e ideas.

Los folletines no fueron del gusto de la prensa conservadora y menos de la católica (puntualmente de la Revista Católica, con la que Sarmiento solía polemizar), ya que consideraban que lo que allí se difundía iba en contra de la religión. El folletín biográfico, pese a exaltar a personajes "honorables", tampoco fue bien visto por los sectores religiosos, debido a que mientras que los periódicos conservadores y religiosos difundían hagiografías y textos acerca de gente de Iglesia, las biografías heroicas que revisamos en este artículo destacaban cualidades sociales, cívicas y militares que nada tenían que ver con la divinidad. De allí que la prensa que abrazó a estos folletines fue la de tendencia liberal que propugnaba la laicización del Estado, y que rechazaba el período colonial por considerarlo oscuro y cegado por la "superchería" católica.

Por último, en las biografías, tanto por sus temas como por las estructuras de estas, quedan de manifiesto las contrariedades de los sujetos escriturales "modernos", quienes escribieron siguiendo modelos trasplantados, pero respecto de temas que los lectores locales debían entender y apropiarse.

\section{Obras citadas}

\section{Revistas}

La Linterna, No 6, 29 de septiembre de 1867.

La Patria, 2 de agosto de 1845.

La Patria, 22 de noviembre de 1845.

El Progreso, No 83, 18 de febrero 1843.

La Revista Americana, 29 de agosto de 1869.

\section{Libros}

Acosta, Carmen. Lectura Y Nación: Novela Por Entregas En Colombia, 18401880. Bogotá: Universidad Nacional de Colombia, Facultad de Ciencias Humanas, Departamento de Literatura, 2009. 
Alvarado, Marina. Revistas culturales chilenas del siglo XIX (1842-1894): Historia de un proceso discontinuo. Santiago de Chile: Ediciones Universidad Católica Silva Henríquez, 2015.

Amaro, Lorena. Vida y Escritura: Teoría Y Práctica de la Autobiografía. Santiago, Chile: Ediciones Universidad Católica de Chile, 2009.

Arfuch, Leonor. El espacio biográfico: dilemas de la subjetividad contemporánea. Buenos Aires: Fondo de Cultura Económica, 2002.

Aristóteles. Retórica. Madrid: Gredos, 1999.

Barros Lémez, Álvaro. Vidas de papel. El folletín en América Latina en el siglo XIX. Montevideo: Monte Sexto, 1992.

Berger, Silvia. Cuatro Textos Autobiográficos Latinoamericanos: Yo, Historia e Identidad Nacional En A. Gerchunoff, M. Agosín, A. Bioy Casares y O. Soriano. New York: P. Lang, 2004.

Cánepa, Gina. "Folletines Históricos Del Chile Independiente Y Su Articulación Con La Novela Naturalista". Revista de crítica literaria latinoamericana, Año 15, no. 30 (1989): 23-34.

Ferreras, Juan Ignacio. La novela por entregas, 1840-1900: concentración obrera y economía. Editorial. Madrid: Taurus, 1972.

Garrels, Elizabeth. "El Facundo como folletín". Revista Iberoamericana, vol. LIV, núm. 143 (1988): 419-447.

Habermas, Jurgen. Historia y crítica de la opinión pública. México D.F.: Ediciones G.Gili, 1994.

Lahire, Bernard. El hombre plural. Los resortes de la acción. Barcelona: Edicions Bellatierra, 2004.

Laera, Alejandra. El tiempo vacío de la ficción: Las Novelas Argentinas de Eduardo Gutiérrez y Eugenio Cambaceres. Buenos Aires: Fondo de Cultura Económica, 2004.

Narvaja de Arnoux, Elvira. Los discursos sobre la nación y el lenguaje en la formación del Estado (Chile 1842-1862). Estudio glotopolítico. Buenos Aires: Santiago Arcos editor, 2008.

Piña, Carlos. La construcción del "sí mismo" en el relato autobiográfico. Santiago, Chile: FLACSO, 1988.

Poblete, Juan. Literatura chilena del siglo XIX: entre públicos lectores y figuras autoriales. Santiago de Chile: Editorial Cuarto Propio, 2002.

Rama, Ángel. La ciudad letrada. Santiago de Chile: Tajamar Editores, 2004.

Ramos, Julio. Desencuentros de la modernidad en América Latina: Literatura y Política en el siglo XIX. Santiago, Chile: Editorial Cuarto Propio, 2003.

Sarlo, Beatriz. Una modernidad periférica: Buenos Aires 1920 y 1930 . Buenos Aires: Nueva Visión, 1988.

Subercaseaux, Bernardo. Historia de las ideas y la cultura en Chile. Fin de siglo: la época de Balmaceda. Tomo II. Santiago de Chile: Editorial Universitaria, 1997.

\section{Capítulos de libro}

Alvarado, Manuel. "Héroes de papel. La figura heroica en las páginas de las primeras revistas culturales chilenas (1842-1858)". Jaime Galgani y Marina Alvarado (editores). Revistas Culturales: Transformaciones de la prensa desde el siglo XIX al XXI. Santiago de Chile. 2016 (en preparación).

Jaksic, Iván y Sol Serrano. "El gobierno y las libertades. La ruta del liberalismo chileno en el siglo XIX". Iván Jaksic y Eduardo Posada Carbó (editores). 
Liberalismo y poder. Latinoamérica en el siglo XIX. Santiago, Chile: Fondo de Cultura Económica, 2011.

Morales, Leonidas. "Prólogo". Luis Oyarzún. Diario Íntimo de Luis Oyarzún. Santiago de Chile: Edición Departamento Estudios Humanísticos del Departamento de Ciencias Físicas y Matemáticas de la Universidad de Chile, 1995. 2-20.

\section{Artículos de revista}

Acosta, Carmen. "Leerse en la novela y formar parte de la cultura nacional (Colombia a mediados del siglo XIX)". Orbis Tertius, XVII, No 18 (2012): Disponible en <http://www.orbistertius.unlp.edu.ar/article/ view/OTv17n18d02

Bourdieu, Pierre. La ilusión biográfica. Acta Sociológica 56 (2011): 121-128.

Fernández, Bravo A. "La Frontera Portátil: Nación y Temporalidad en Lastarria y Sarmiento". Revista Iberoamericana 63 (1997): 141-147.

Larraín, Jorge. "La trayectoria latinoamericana a la modernidad". Estudios Públicos 66 (otoño 1997): 313-333.

Narvaja de Arnoux. "Elvira. Marcar la nación en la lengua: la reforma ortográfica chilena (1843-1844)". Ámbitos: revista de estudios de ciencias sociales y humanidades 16 (2006): 41-53.

Pas, Hernán. "La educación por el folletín: prácticas de lectura y escritura en la prensa latinoamericana del siglo XIX". Cuadernos Americanos: Nueva Época (Volumen 1, No 151, 2015): 37-61.

\section{Presentaciones en congresos}

Alvarado, Marina. "Biografías folletinescas en la prensa chilena del siglo XIX". Jornadas Vidas Ajenas: perfiles, retratos y biografías latinoamericanos, Pontificia Universidad Católica de Chile y Centro de Investigación y Documentación de la Universidad Finis Terrae. 24-25 Mayo, 2016. Ponencia.

Pinto, Julio. "De Proyectos y Desarraigos: La sociedad latinoamericana frente a la experiencia de la Modernidad (1780-1914)". 19th International Congress of Historical Sciences, University of Oslo. 6-13 Agosto, 2000. Ponencia. 